\title{
Philippe Steiner e a Sociologia Econômica: trajetória, redes internacionais, afinidades teóricas e objetos de pesquisa
}

Bruno Costa Barreiros'

A mesa de madeira, a da entrevista ${ }^{2}$, é a mesa da sala de estar. É uma mesa relevante para a história da sociologia econômica brasileira. Em tempos nos quais o tema "les objets dans l'action" ganha os espaços de discussão da sociologia francesa, falar sobre a mesa da entrevista parece um bom ponto de partida para introduzir essa conversa com Philippe Steiner. "Como a sua relaçáo com o Brasil começou? ", lhe perguntei em determinado momento. A resposta que se sucedeu foi interessante: "Ela começou aqui onde você está, nesta mesa! ”. Foi exatamente ali onde as primeiras conversas tête à tête ocorreram entre Philippe Steiner e a entáo professora da Universidade Federal de Santa Catarina (UFSC), Cécile Raud, no início dos anos 2000. Esse é um marco importante para a emergente sociologia econômica brasileira: a abertura de mais um canal de circulação de pesquisadores e suas ideias entre a França e o Brasil.

Leitor da obra de Steiner desde 2013, o conheci numa conferência da ANPOCS em 2016. Foi apenas uma saudação e o cumprimento por

1 Doutorando e mestre em Sociologia Política pelo Programa de Pós-Graduação em Sociologia Política da Universidade Federal de Santa Catarina, com periodo de estágio doutoral na École Normale Supérieure de Paris. Membro do Núcleo de Sociologia Econômica (NUSEC) e do METROPOLIS - Laboratório de Pesquisa Social. Bolsista CNPq. Email: barreirosbc@gmail.com

2 Agradeço ao CNPa pela bolsa SWE que tornou possivel a minha estadia na França e a realização dessa entrevista.

\section{$(\mathrm{cc}) \mathrm{Br}$}

Direito autoral e licença de uso: Este artigo está licenciado sob uma Licença Creative Commons. Com essa licença você pode compartilhar, adaptar, para qualquer fim, desde que atribua a autoria da obra, forneça um link para a licença, e indicar se foram feitas alterações. 
uma conferência inspiradora. Contudo, foi em uma reunião do Groupe de Recherche Interdisciplinaire sur le Politique (GRIP) na École Normale Supérieure (ENS), destinada a debater a obra dele e seu percurso acadêmico, que consegui conversar um pouco mais com o professor Steiner. Falando, dentre outras coisas, sobre o Brasil, descobri um Steiner fascinado pelo nosso país e com muita história para compartilhar. Dias depois, lhe apresentei uma proposta de entrevista. $\mathrm{O}$ aceite veio logo em seguida, junto com o convite para que a conversa fosse em sua casa.

Philippe Steiner é autor de mais de uma dezena de livros consagrados sobre a sociologia econômica, a economia política, os mercados, a sociologia de Durkheim, o altruísmo, a moral e o transplante de órgãos, originalmente publicados em francês, mas com traduçóes para o espanhol, o português, o italiano e o inglês, além de um número ainda maior de capítulos de livros e artigos sobre esses assuntos. Professor de sociologia da Université Paris-Sorbonne, fez a sua formação acadêmica tanto nas ciências sociais como na economia, o que ajuda a explicar seu interesse pela sociologia econômica.

A entrevista ${ }^{3}$ que o leitor encontra adiante foi feita no dia 16 de março de 2018 no apartamento de Philippe Steiner. Autour d'un café, nos sentamos à mesa, a da sala do apartamento de Steiner no sul da capital francesa. É o mesmo cenário que caracterizou tantas discussóes com pesquisadores brasileiros em doutorados-sanduíche, em pós-doutorados ou em passagens mais breves pela França. A conversa, cujo registro integral traduzido para o português o leitor aqui encontra, aborda o processo de conversão de Philippe Steiner para a sociologia econômica, a relação dele com os economistas, a percepção que tem sobre a disciplina da economia e o trânsito de ideias com a sociologia, as redes internacionais de pesquisadores da sociologia econômica e a sua visão sobre esse campo de estudos no Brasil, a afinidade teórica com Weber e Durkheim, e o seu objeto de interesse de pesquisa atual, as festas.

3 A entrevista durou 72 minutos. $A$ transcrição em francês e a tradução para o português foram feitas pelo entrevistador ao longo de abril de 2018. Esta entrevista foi revisada por Philippe Steiner em junho de 2018. 
Entrevistador - Poderíamos começar esta entrevista a partir de um artigo de 2005 (Pourquoi la sociologie économique est-elle si développée en France ?), no qual você começa perguntando: "Como explicar o interesse pela sociologia econômica na França a partir dos anos 1990? Como explicar a forte presença de economistas neste campo de pesquisa?" (STEINER, 2005, p. 391, tradução nossa). Dirijo estas perguntas a você, como pesquisador da sociologia econômica, para saber um pouco mais sobre seu momento de conversão à sociologia econômica, se podemos falar disso: como isso aconteceu?

Philippe Steiner (P. S.) - No meu caso, aconteceu quando eu tive que ensinar sociologia, quando consegui colocar o pé na universidade, em Paris Dauphine. Eu tinha feito uma formação dupla, em economia e em sociologia, e optei pela primeira, com um doutorado em economia, mas não conseguia encontrar um emprego. Finalmente, consegui ser nomeado para a Universidade de Dauphine, porque eu era um agrégé em ciências sociais ${ }^{4}$. Contudo, os agrégés em ciências sociais não podiam ensinar economia, tinham que ensinar sociologia. Comecei a trabalhar mais intensamente na sociologia e tive muitos anos para ler sistematicamente Durkheim, Weber, Pareto, Tarde, Simmel e Elias. Eu li muito os sociólogos para preparar minhas aulas de modo satisfatório e percebi que eles falavam muito sobre economia. Então, eu pensei: “veja só! Há algo de interessante aí! ”. E estes são os anos de 1985 a 1988. Na época, aqui na França, não havia nada nessa parte do discurso sociológico que tratasse da economia. E eu acredito que, a nível internacional, não havia grandes coisas tampouco, porque o primeiro grande texto (Economic sociology: past and present) sobre esta questão é publicado em 1987 por Richard Swedberg na Current Sociology. Então, lá estava eu trabalhando sobre esses autores e daí eu registro um monte de coisas sobre economia. E na época com um colega, Jean Jacques Gislain, que permaneceu economista e se tornou professor no Canadá, nós refletimos sobre a ideia de fazer uma história da sociologia econômica do período de 1890 a 1920 . E então, se há uma conversão no sentido disciplinar, é nesse momento que ela ocorre. Agora, o artigo ao qual você se refere

4 Na França, o agrégé en sciences sociales é o individuo que passou no concurso agrégation para se tornar professor de ciências sociais. A escolha aqui foi por manter a palaura em francês. (N. T.). 
visava outra coisa da qual sou parte interessada. Trata-se da característica, digamos, do sistema escolar francês, de toda a parte do sistema escolar que forma os professores do ensino médio. E o argumento que eu tinha desenvolvido no artigo de 2005 é o de dizer: existe algo particular na França, em parte porque se propóe a ensinar ciências econômicas e sociais razoavelmente cedo, desde a década de 1960, com o objetivo de oferecer uma cultura econômica à população do pós-guerra e depois isso se institucionaliza nos anos 1970. O sistema francês almeja que se houver um ensino de algo, devem existir professores treinados para tanto. Criam-se, assim, processos de recrutamento e, por fim, será criada uma agrégation. Bem, isso pode não parecer muito interessante, mas acho que, pelo contrário, isso é importante na medida em que teremos, digamos, um certo prestígio do ensino superior francês, uma combinação rara. Nas Écoles Normales Supérieures, primeiro a ENS de Cachan, depois em Lyon e na rua d'Ulm em Paris, veremos filières 5 nas quais as pessoas devem estudar, ao mesmo tempo, sociologia, história e economia. Ademais, frequentemente, é preciso que eles tenham uma boa formação em estatística e em modelagem matemática. Então, existem pessoas muito bem treinadas em ambos os domínios, além de história e matemática, que passam pelos concursos prestigiados na França. O fato de ser agrégé é valorizado. Então, basicamente, há algo de peculiar que é colocado, isto é, há pessoas que seguem as filières de ensino consideradas como de prestígio, que passam pelos concursos, que continuam prestigiados e com essa dupla formação considerada legítima. Eu segui esta formação e pessoas como Frédéric Lebaron e Michel Lallement também seguiram essa formação, e agora uma quantidade de jovens sociólogos econômicos também. Portanto, temos na França uma espécie de elite da formação professoral que tem esta dupla formaçáo e para quem a sociologia econômica não é, em última análise, algo marginal, mas sim uma forma de especializaçáo e que não é dominada. Ela tem um prestígio real. Bem, eu digo prestígio, o que pode parecer exagerado, mas é simplesmente para dizer que não é uma formação subvalorizada ou dominada.

Entrevistador - É realmente bem interessante. Mas por que exatamente estudar e trabalhar nesse campo de pesquisa da sociologia econômica?

5 A palaura francesa filière carece de uma correspondente em termos de sentido na língua portuguesa. Aproxima-se das noções de "processo", "via" e "canal". A escolha aqui foi por manter a palaura em francês. (N. T.). 
Quais seriam as opçóes que você tinha no momento de conversão, se podemos falar disso?

P. S. - A conversão é feita em dois momentos. Porque quando eu fiz esse primeiro movimento para a sociologia econômica, com o livro publicado em 1995, isso continua um pouco no domínio que era o mesmo da minha tese, isto é, o que chamávamos e o que ainda chamamos de história do pensamento econômico. Essa foi a área para a qual, depois de ter realizado esses estudos de econometria e de economia matemática, eu enveredei. Por isso, quando eu escrevi este livro, ele continua fundamentalmente como história das ideias. E assim a conversão é feita num primeiro momento desta maneira. Eu continuo um pouco também, em seguida, com o meu livro sobre a escola durkheimiana, mas depois eu me interesso mais diretamente pela sociologia econômica. Acerca disso, tem o meu livro de 1999 apresentando a sociologia econômica contemporânea (STEINER, 2006). Ao mesmo tempo, isto é, por volta de 1998 e 1999, começo a pensar em uma pesquisa que seria mais empírica, de certa forma, em um domínio da sociologia econômica um pouco mais particular que é o das transaçóes no âmbito dos transplantes de órgãos. E assim há uma conversão em dois momentos, de certa forma. A primeira conversão, se vamos resumir assim, na segunda metade dos anos 1980, quando eu descubro o fenômeno da sociologia econômica e, digamos, uma década depois, quando me interesso pela sociologia econômica contemporânea e "eu escolho" um terreno mais empírico com o transplante de órgãos. Aí, eu me torno um pouco mais sociólogo. Eu deixo em parte a dimensão de história das ideias, mesmo que eu sempre tenha mantido um ouvido atento a isso, um interesse por esse tipo de coisa, mas deixo a história das ideias para me interessar por coisas mais contemporâneas. Atualmente, eu tento trabalhar em ambas as frentes, quando é possível, mas, veja bem, a verdadeira conversão pode ser que esteja aí, do ponto de vista do sociólogo.

Entrevistador - Aqui também lembramos que você tem uma formação em economia. Você acabou de falar a respeito. Sobre isso, como você tomou sua decisão de estudar a disciplina econômica? Agora, voltamos um pouco mais no passado...

P. S. - Bem, por ter interesse pela compreensão dos sistemas de pensamento... jamais me fiz essa pergunta. Provavelmente, um elemento de 
explicação deve estar no fato de que, quando estava nos cursos preparatórios para entrar na École Normale Supérieure de Cachan, era, ao mesmo tempo, obrigado a seguir os ensinamentos da universidade. A formação ocorria nas aulas preparatórias, mas, para passar no concurso, era preciso ter validado os dois primeiros anos da universidade em economia. E, nesse momento, eu estou na Universidade de Reims, a cidade do champanhe, embora eu não o bebesse muito na época! E a Universidade de Reims era uma universidade dominada por professores marxistas. Quando consideramos Marx em toda a sua obra, há $O$ Capital e os três volumes denominados História da mais-valia. Então, o ensino lá era muito carregado de história do pensamento econômico. Muito fortemente. E assim, talvez desde o início, eu tenha tido um certo interesse pela história do pensamento econômico, porque era um elemento importante da formação, acredito que na França em geral, mas especialmente na Universidade de Reims. E, além disso, estudamos muito Marx na Universidade de Reims. Marx é um autor muito próximo, de um certo modo, da sociologia econômica, pois ele estuda as sociedades a partir de um ponto de vista econômico, mas com uma dimensão social: a teoria das classes, as relaçóes sociais como elemento essencial da compreensão da vida econômica e, portanto, esse tipo de combinação entre economia, política e sociedade foi, enfim, o que aprendi desde que cheguei à universidade. Porque, antes disso, no ensino médio, eu estudava essencialmente matemática e física. E assim eu descubro isso na universidade, o que se intensifica com a história das ideias, e acho que isso deve ter permanecido em meu espírito. É por isso que eu acho que devo ter tomado esse rumo. Depois, eu fiz as duas conversóes das quais acabamos de falar.

Entrevistador - Agora, falemos da sua relaçáo com os economistas. Como você descreveria seu relacionamento com os economistas: caracterizado mais pela tensão-competição, como muitos sociólogos da tradição francesa (e.g., Comte, Durkheim e Bourdieu) ou pela cordialidade-cooperação, como aqueles que aderem às abordagens mais inspiradas por Weber?

P. S. - Quando eu chego à universidade como professor, sou nomeado como sociólogo, mas depois de três ou quatro anos, eu alcanço um cargo de mestre de conferências (i.e., maître de conférence) em economia. 
Sou bem acolhido, sou um historiador do pensamento econômico. É um rumo que é razoavelmente marginal na economia política francesa. Nos anos 1980, ainda é algo reconhecido, mas que está em declínio. Esse é o sentimento que extraio disso agora. Bem, é isso... é assim, mas no meio dos historiadores do pensamento econômico, sou recebido sem problemas. Não há dificuldade. E então adquiro, de certa forma, creio eu, a apreciação de meus colegas pelos trabalhos de história do pensamento econômico que fiz e, assim, sou razoavelmente bem integrado nesta comunidade. Beneficio-me, em seguida, de uma chance fantástica, pois meu colega que já era professor, Gilbert Faccarello, que tinha estado em Dauphine, mas que não estava mais quando cheguei lá, viria a fundar um centro de pesquisa em outra ENS, em Fontenay aux Roses. Ora, ele me levou ao seu laboratório, entáo foi muito bom, e a chance que tive foi que ele tinha uma certa quantidade de recursos, as ENSs têm mais recursos do que as universidades, e eu também pude me beneficiar na época de passagens aéreas para ir ao exterior e de uma coisa muito importante que foi um serviço, que não era exatamente de tradução, mas de edição de meus textos em inglês, em um inglês publicável. Como na época Faccarello não se deslocava muito e os outros não queriam ir para os Estados Unidos, eu tinha quase a possibilidade de ir uma ou duas vezes por ano em conferências internacionais na Europa ou nos EUA com textos em um bom inglês. É assim que escrevo minha história pessoal. Sou assim rapidamente admitido na comunidade internacional entre as pessoas que trabalham lá e que são ativas em termos de publicação. Então minha inscrição neste domínio é feita sem dificuldade. Depois, existem coisas mais ambíguas, na medida que é a partir dos anos 1990 e 1992 o momento em que começo a escrever sobre a questáo da sociologia econômica: o meu primeiro artigo sai na Revue Française de Sociologie de 1992 sobre o fato social econômico em Durkheim. Entáo, foi nos anos 1990 que comecei a fazer isso. Aí aparecem reaçóes mistas de economistas, incluindo historiadores do pensamento econômico. Há aqueles que dizem "uh lá lá! A sociologia econômica não é realmente uma boa ideia. Não se engaje nisso". E a razão pela qual eles dizem isso é que houve um primeiro movimento de sociologia econômica na França da parte dos economistas nos anos 1950 e 1960 em torno da Revue Économique. E essa abordagem é considerada como "velha", "um beco sem saída", "uma perda de tempo", 
em comparação com a economia que é matematizada, mais formal, etc. Então, há economistas que dizem “uh lá lá! Isso não é bom!». Eu sinto que ela não os entusiasma. E depois há outros economistas, mais próximos da economia industrial, de uma visão mais ampla de economia, que eles, desde o começo, e me lembro bem em 1991 durante um colóquio que tinha ocorrido na França, no qual alguém importante me disse "é bom o que você faz, é preciso que você continue". Então, havia opinióes bastante divergentes, mas, de um modo geral, foi tranquilo. Eu não tive nenhum conflito nesse sentido, mesmo se, em relação à pergunta mais específica que você me fez, na época eu tivesse uma visão mais do tipo durkheimiana, isto é, a sociologia econômica se opóe à economia neoclássica, mainstream, etc. Então, desse ponto de vista, isso poderia ter sido conflituoso, mas não foi.

Entrevistador - Interessante. E em relação às tendências da economia, como você vê as tendências da disciplina econômica e quais são as possibilidades de relação entre sociologia e economia atualmente?

P. S. - Então... eu acho que há uma diferença muito forte com relação à economia que eu aprendi, a economia dos anos 1970. Basicamente, se tratava dos modelos macroeconômicos e de uma microeconomia que era bastante convencional. A microeconomia da incerteza não existia na época em que eu era estudante. A teoria dos jogos estava apenas começando a se desenvolver nas aulas. Então, tínhamos uma economia que era consideravelmente rígida, formal e macro. A teoria econômica contemporânea ainda tem essa dimensão e é intensificada por uma matematização muito mais sofisticada, o que torna a leitura mais opaca para muitas pessoas e para mim também. De qualquer forma, parece-me que, neste momento, as coisas mudaram muito com opçóes que eu diria que se abrem na direção de reaproximações possíveis e flutuantes. Então, obviamente, existem todas as correntes com as quais o diálogo é consideravelmente fácil - a economia das convençóes, a economia da regulação, todas as escolas institucionalistas - podemos discuti-las e encontrar os pontos de ligação facilmente. $\mathrm{Na}$ medida em que se fala de instituições, normas, regras, da história, que é obviamente muito importante, a relação com as ciências sociais, de forma geral, é razoavelmente fácil. Mas mesmo com economistas muito mais convencionais, existem possibilidades. Então, vou me referir agora a coisas 
que me interessam e que descobri com o transplante de órgãos, sobre as quais eu ainda estou trabalhando atualmente. Trata-se, digamos, do tema do "economista como engenheiro". Alvin Roth não é absolutamente um sociólogo econômico, mas com a sua maneira muito formalizada de fazer economia, ele abre perspectivas sobre os processos sociais, que ele descreve muito bem, a seu modo, mas que ele não investiga. É daí que vem o conceito de matching markets; podemos ver a estrutura social por trás, mas que ele não estuda. E eu acho que é aí que os sociólogos podem fazer os seus trabalhos, pegando uma parte dos resultados dele e acrescentando-lhes as suas concepçóes, o que remete basicamente à perspectiva weberiana de combinação entre os dois lados, o que é muito bom. Veja que esse é um exemplo importante para mim, pois eu trabalho nessa perspectiva. Outra perspectiva que também me parece muito interessante está no fato de que a partir da intermediação de grandes bases de dados, que servem como materiais empíricos aos economistas para avançarem em suas modelagens, se alcança um desenvolvimento muito importante na teoria econômica contemporânea. E aqui eu penso em Thomas Piketty: mesmo se, na época, ele estava menos conhecido pela questáo dos altos salários na França, o seu trabalho como historiador é muito próximo, de certa forma, de uma combinação entre ciências sociais e economia. Thomas Piketty é alguém que publica nas melhores revistas dos economistas. Então, ele oferece possíveis convergências sobre, veja bem, a estruturação social que corresponde a essa hierarquia na distribuição dos patrimônios, das rendas, sua evoluçáo com base em fenômenos históricos, sociopolíticos, mesmo pela herança, etc. Assim, há toda uma gama de fenômenos provenientes dos economistas que não se opóem aos sociólogos e até, de certa forma, convocam o trabalho dos sociólogos para irem mais longe. Cito esses dois domínios porque são domínios que estudei mais do que outros, mas, veja bem, me parece que existem oportunidades reais para o trabalho comum.

Entrevistador - Mesmo se falarmos de engineering economics ou de design economics, que representam a fronteira entre economia e engenharia, até nesse sentido existe a possibilidade de trabalho comum entre sociólogos e economistas?

P. S. - Sim. Acho isso porque justamente se estudamos Design Economics de Alvin Roth, descobrimos lá a maneira por meio da qual se modelam e se 
colocam as instituiçôes de mercado. Nesse sentido, o economista trabalha à sua própria maneira, obviamente, sobre o modo de estabelecer as preferências, que o sistema seja estável, que não haja manipulação, que não haja oportunismo, etc., que as pessoas tenham um interesse em fazer as trocas nesta instituição e não em outros lugares. Portanto, há um punhado de problemas próprios aos economistas. Mas isso favorece, de certa forma, o trabalho do sociólogo, o que não significa que vamos o tempo todo se alinhar com eles: podemos nos opor a eles. Por exemplo, oponho-me fortemente à ideia de matching markets no caso de transplante de órgãos. É um matching, mas não é do mercado, então podemos estar em desacordo, mas me parece que isso abre perspectivas nas quais os sociólogos podem trabalhar e trazer suas contribuiçóes. Além disso, no final do meu último livro sobre altruísmo (STEINER, 2016a), não vejo razões pelas quais os sociólogos não possam também começar a fazer design, de estabelecer as arenas de trocas um pouco mais particulares, a partir do momento em que vão se basear não nos problemas da eficiência econômica no sentido dos economistas, mas sim nos problemas da justiça social, nos problemas que devem evitar que as pessoas que estejam bem posicionadas na estrutura social e com vantagens em relação àqueles com menos capital social, capital cultural e capital econômico, se aproveitem disso, como pode ser o caso da escola, por exemplo. Parece-me que os sociólogos que tenham uma formação de matemática aplicada, como muitos economistas têm, poderiam fazer algum trabalho de design para estabelecerem as trocas, que não seriam necessariamente mercantis. Poderiam ser, mas não necessariamente, fazendo valer critérios que não são aqueles que os economistas normalmente estudam. Portanto, mesmo nesse caso, não vejo porque os sociólogos não possam fazer o que os economistas fazem.

Entrevistador - Agora, mudamos um pouco de assunto e falamos sobre a sociologia econômica e a dinâmica internacional. Pode-se afirmar que existe há alguns anos uma rede internacional de pesquisadores da sociologia econômica. Como você vê essa rede atualmente?

P. S. - Então, há uma rede, digamos, informal, na qual eu acho que várias pessoas podem ter canais diferentes, é claro, no sentido de que há uma seçáo de sociologia econômica na American Sociological Association (ASA), onde os europeus e outros não-estadunidenses podem contribuir, 
mesmo que nem sempre seja tão fácil. Fiz sugestôes que nunca foram selecionadas para a ASA, mas eu não devo ter feito o que era preciso. Em um dos casos, me disseram claramente: "estamos no cenário americano, somos muito coerentes e, portanto, não escolhemos você”. Isso significa que nessas aberturas internacionais das associaçóes nacionais podem ocorrer momentos de fechamento assim. Então, existe essa forma e há também a European Sociological Association, que organiza encontros na Europa para a sociologia econômica, onde há, às vezes, seniors, juniors, etc. No nível das grandes instituiçóes, existe essa possibilidade de se reunir, de discutir a nível internacional. Há também a SASE (Society for the Advancement of Socio-Economics) e a Association Internationale des Sociologues de Langue Française (AISLF). Então, existem várias redes e cada uma tem uma dimensão de sociologia econômica. Acho que, desse ponto de vista, isso funciona bem. Também teria tendência a sublinhar a importância crescente de jovens colegas que passaram por intercâmbios internacionais, como você de certa forma, e que, no caso França-Brasil, permitem que jovens pesquisadores brasileiros estudem na Europa. Não sei se há muitos franceses que saem para estudar no Brasil. Mas, de todo jeito, há professores que se deslocam e, portanto, há trocas reais, redes reais que podem existir, mas que estão muito relacionadas às pessoas que as operam. Existe uma em particular que me parece ter uma amplitude considerável com a rede que gira entorno do Max Planck de Colônia (Alemanha), que atualmente é dirigido por Jens Beckert. Parece-me que o Max Planck tem uma vocação internacional, uma vez que recruta cerca de dez estudantes de doutorado no nível internacional a cada ano. Eles podem vir da América do Sul, dos Estados Unidos... um pouco menos, mas acontece, da Europa, Ásia, etc. E durante as últimas audiências das quais eu participei no Max Planck, vemos aparecer entre eles a preocupação de utilizar uma certa reunião internacional, a SASE, para reunir os ex-alunos do Max Planck a fim de estruturar a rede internacional deles que está sendo criada. Além do mais, o Max Planck tem uma ligação com a Sciences Po, o chamado Max-Po, que reforça essa ligação internacional entre a França e a Alemanha, e aí podemos ver bem esse tipo de rede mais estruturada do que as redes interpessoais que eu possa ter com colegas de São Paulo, com Nadya Guimarães ou com outros no Brasil, dos Estados Unidos com Richard Swedberg ou Marion Fourcade 
em Berkeley, etc. Estas são redes mais pessoais, que podem se solidificar, mas não necessariamente, embora tenhamos também essas estruturas em nível internacional. E há a famosa newsletter editada pelo Max Planck, que acredito que federaliza essa internacionalizaçáo da sociologia econômica.

Entrevistador - Eu gostaria de pedir que você falasse um pouco mais sobre a sociologia econômica nos Estados Unidos. Como você vê a diferença entre a sociologia econômica praticada aqui na França? E se é possível fazermos um bloco da Europa com França, Alemanha e Grã-Bretanha, por exemplo - e, de outro lado, a sociologia econômica praticada nos Estados Unidos? Quais são as diferenças?

P. S. - Eu não acho que exista diferenças fortes entre os Estados Unidos e a Europa em geral. Parece-me que há um grande número de intercâmbios. Quando eu fiz o livro sobre sociologia econômica, eu me baseei muito nos trabalhos de Granovetter, White, Zelizer, Fligstein, então eu acho que, com bastante frequência nos Estados Unidos, tem uma certa quantidade de pesquisadores de grande prestígio. Granovetter marcou terreno, Swedberg também o fez bastante. Swedberg é um bom exemplo porque é um universitário sueco que leciona há muito tempo na Universidade de Estocolmo e que há uns quinze anos é professor na Cornell University, uma das principais universidades americanas. Isso mostra bem como alguém pode ir de um lado para o outro. Marion Fourcade, que é francesa de origem, também fez sua tese nos Estados Unidos e ela é professora em Berkeley. Existe, na minha opinião, uma possibilidade para fazer trocas com bastante facilidade. Além do mais, Granovetter foi bem acolhido pelos que trabalham com economia das convençóes com muita facilidade, como alguém que fazia obras no mesmo sentido que eles. Viviana Zelizer tem uma conexão forte com Florence Weber na École Normale Supérieur em Ulm. Portanto, tenho a sensação, ao contrário, de que isso circula bem e que existe um tipo de comunidade bastante ampla entre colegas americanos e colegas europeus. Uma vez que dizemos isso, acho que existem, apesar de tudo, especificidades francesas. Primeiro, há esse fato maciço da presença de Pierre Bourdieu. Ele tem uma importante dimensão da sociologia econômica em sua obra Les structures sociales de l'économie de 2000. E aqui acabamos de lançar seu curso de 1992-1993 chamado Anthropologie Économique. Bourdieu tem um lugar muito importante na sociologia mundial e, 
considerando a sociologia econômica que ele desenvolveu, obviamente é alguém que marca. De certa forma, há uma sociologia econômica bourdieusiana no mundo inteiro. E também há autores como Luc Boltanski e Laurent Thévenot que colocaram em prática uma maneira de articular a economia, a política e o social, por meio do conceito de cité. O tema dos objetos em ação é algo que se desenvolveu rapidamente na França e depois foi levado em conta por essa orientação pragmática de Boltanski. E isso é muito desenvolvido por Michel Callon e Bruno Latour, que também trazem, me parece, algo de original, de novo. O último livro de Michel Callon é muito original, muito abrangente; é toda uma sociologia econômica que ele propóe a partir de um longo trabalho de vinte anos e acho que isso marcará o terreno novamente. Boltanski também publicou um livro sobre o enriquecimento, para o qual tenho uma opinião mais moderada, mas que também é uma proposição importante. Então eu acredito que existe, no caso francês, um movimento verdadeiro com suas particularidades na abordagem seguida pelos sociólogos econômicos. Eu me lembro de um colóquio onde eu estava ao mesmo tempo que Laurent Thévenot e se tratava de orientar um pouco como os volumes das atas do colóquio tinham sido organizados. E nós estávamos sintonizados de alguma forma, ele e eu, para intervir cada um à sua maneira, mas para levar a uma direção. E nós falhamos completamente. Os colegas americanos não ouviam o que dizíamos. Eles ainda têm um estilo que os leva a favorecer certas coisas mais do que outras. É mais uma diferença de estilo do que de fundamento, já que os colegas franceses estão muito familiarizados com o que está acontecendo nos Estados Unidos e eu acho que há alguns americanos que veem muito de perto o que está ocorrendo na França. Então, há uma circulação, como a que existe com o Brasil.

Entrevistador - E agora falamos sobre o Brasil. Sabemos do seu relacionamento com colegas brasileiros e de que náo é raro vê-lo ministrando conferências no Brasil. Como a sua relação com a sociologia brasileira começou?

P. S. - Ela começou aqui onde você está, nesta mesa! Porque Cécile Raud Mattedi, que na época era professora da universidade de Florianópolis [UFSC], desejava fazer seu pós-doutorado sob minha direção e, então, em um dado momento, ela entrou em contato comigo, ela veio e nós 
discutimos como estamos discutindo agora, a respeito do pós-doutorado que ela veio fazer. Depois disso, ela tentou me levar para Florianópolis e náo deu certo. Foi em 2005 e náo deu certo...

Entrevistador - Por que não?

P. S. - Por causa do financiamento. Então, ela me disse que faríamos de outra forma e ela fez contato, eu acho, com Ricardo Abramovay, quem recomeçou o negócio no ano seguinte e, provavelmente, porque veio de alguém dotado de um status muito mais elevado, ele estava na USP e não em Floripa, aí isso pôde funcionar. Assim, fiz minha primeira estadia no Brasil em agosto de 2006 na FEA-USP com o Ricardo e eu encontrei Cécile em Florianópolis, fiz contato e isso continuou com colegas brasileiros que vinham fazer o seus pós-doutorados ou doutorados-sanduíche comigo em Paris e nós pudemos desenvolver o negócio. Talvez, o que ajudou também é que em 2006, quando eu cheguei, o volume de sociologia econômica tinha sido traduzido por uma colega da Fundação Getulio Vargas. É possível que isso tenha ajudado a montar o projeto e isso me permitiu encontrar também os colegas da Fundação Getúlio Vargas e construir uma primeira rede menor e que depois passou a se fortalecer. E devo dizer que gostei muito, desde o início, do encontro com os colegas brasileiros, porque oferecia uma perspectiva diferente daquela com a qual eu estava acostumado na Europa e talvez devido a minha propensão a estudar teorias. No Brasil, há uma dimensão política muito mais presente: em 2006, é o ano em que Lula se apresenta de novo às eleiçôes. Então há essa mudança considerável, apesar de todas as dificuldades que possam... eu não desconheço as dificuldades que Lula está enfrentando atualmente... mas, sem dar uma opiniáo, porque seria ir longe demais para a nossa proposta, ainda tenho lembranças de um Brasil que se orgulhava dele. Naquela época, havia algumas mudanças muito importantes: o Bolsa Família, por exemplo, é algo que fez uma grande mudança, no meu ponto de vista. E assim os colegas brasileiros estavam investidos em tecer uma relação mais próxima com as questóes políticas e achei isso muito interessante, isso renovou um pouco a maneira como eu refletia sobre esse assunto. Ademais, na época, eu estava trabalhando mais ativamente sobre o transplante de órgãos. E o transplante de órgãos tem uma dimensão política importante. Então, dos dois lados, via surgir coisas que não tinha visto aparecer. Em seguida, há uma riqueza 
na abordagem: o Brasil é um país grande, tem pessoas com formações muito variadas, interesses variados, há toda uma dinâmica que existe no Brasil, as pessoas se conhecem, discutem uns com os outros na ANPOCS ou em outros lugares. Tudo isso me parece muito interessante. A prova disso é que tenho grande prazer de acolher colegas brasileiros, de contribuir com Nadya [Guimarães] em um projeto comum sobre o matching, mas também com colegas de Aracaju em um projeto que trata da sociologia econômica da festa, etc. O encontro com o Brasil foi extremamente proveitoso para mim e, ademais, extremamente agradável.

Entrevistador - Você já falou sobre a sociologia em geral no Brasil, mas te pergunto agora mais precisamente sobre a sociologia econômica que fazemos no Brasil. Você vê diferenças com a que é praticada na França?

P. S. - Eu diria que há mais diferenças no enfoque que vamos dar a este ou àquele problema, pois há essa dimensão política, quase de política social, que podemos associar a isso. Lembro-me de uma participação em um colóquio de sociologia econômica em Florianópolis onde fui convidado por Cécile [Raud] e vi uma coisa que está à margem da sociologia econômica francesa: não exatamente negligenciável, nem negligenciada, mas, apesar de tudo, à margem, que é a sociologia econômica do mundo agrícola. O mundo agrícola na França é restrito em comparação ao que ele é no Brasil, especialmente as questôes de pobreza ligadas à implementaçáo da agricultura de uma certa população, à dificuldade que esta encontra para comercializar, para ter acesso a crédito. Há todo um conjunto de problemas. E assim fiquei impressionado ao ver o número de comunicações que tratavam dos criadores de cabras de tal região, o problema de comercializar queijo, leite, etc. Isso existe na França, mas permanece confinado a uma pequena subárea da sociologia econômica, enquanto que no Brasil ocupa um lugar enorme. A questão da financeirização, justamente com as reformas de Lula sobre a questáo da previdência, também assumiu uma dimensão muito grande, mas diferente daquela que se pode ter aqui na França. Porque aqui será mais sobre a questão dos traders, enquanto que no Brasil está mais próxima de problemas sociais, problemas políticos, problemas sindicais. Veja só: essa é a orientaçáo ligeiramente diferente que vemos surgir no Brasil, que ainda desperta o meu interesse e que me parece revelar uma certa característica de abordagem seguida. A ligação com a 
questão do mercado de trabalho é muito importante, com os colegas de Porto Alegre, onde Nadya [Guimarães] é especialista no mercado de trabalho, embora seja muito aberta a essas questóes da sociologia econômica. Eu acrescentaria, talvez, um pouco de algo que nós iremos tratar no final porque se refere a coisas que eu estou começando a fazer e que eu não fazia antes: atualmente, minha pesquisa empírica trata da sociologia econômica da festa. Uma vez que descubro esta questão da festa no mundo moderno, na sociologia econômica da festa, encontro muito pouca coisa na França, poucas coisas na Europa e o país no qual encontro coisas interessantes é o Brasil. Nisso, há algo de novo que espero estudar especialmente com Marina Sartore, de Aracajú [UFS], e, eventualmente, com Raquel Weiss, de Porto Alegre [UFRGS], nos próximos anos: trata-se da economia da festa e da economia do turismo, a economia do entertainment, como dizemos em inglês, do lazer, digamos, do lazer festivo. E aqui vamos considerar coisas que foram negligenciadas pela sociologia econômica até o presente momento. Ainda que a festa seja um momento importante na vida social (e.g., o carnaval do Rio), não me parece que tenha sido estudada de uma maneira proporcional à importância que representa para a vida social. Por isso, espero que nos próximos anos possamos iniciar um trabalho conjunto entre os colegas franceses e os colegas brasileiros.

Entrevistador - Esta é uma bela temática, sem dúvida, mas primeiro o convido agora a falar da afinidade com Durkheim. Você é conhecido por ter trabalhado sobre a abordagem durkheimiana. Provavelmente, o principal exemplo seria o livro $A$ sociologia de Durkheim (STEINER, 2016b). Como essa afinidade teórica começou em sua vida?

P. S. - Quando comecei a ter que ensinar sociologia, li Durkheim. Havia uma dimensão econômica muito importante na Division du Travail Social, em alguns capítulos das Règles de la Méthode, toda a parte final do Suicide sobre a questão dos agrupamentos profissionais. Então, há uma dimensáo econômica muito forte em Durkheim. Eu estudei muito isso e quando trabalhei com o meu colega Jean-Jacques Gislain no livro, estudamos Durkheim, Weber, Pareto, Schumpeter, Veblen e acrescentamos um sexto autor, François Simiand, que é talvez menos conhecido que os outros, que são todos conhecidos mundialmente. Ele não é, mas me pareceu importante porque no momento em que Durkheim abandona a dimensão 
econômica da sua pesquisa sociológica, é Simiand quem pega a tocha (i.e., flambeau), sendo muito ativo e com peso na França. Começo então a trabalhar não apenas sobre Durkheim, mas também no vetor que constitui a sociologia econômica durkheimiana, isto é, a Année Sociologique e o seu grupo correspondente. E lá estava eu sistematicamente destrinchando, que é um trabalho de historiador das ideias, então leio sistematicamente doze volumes da Année Sociologique e, assim, vejo o imenso trabalho feito por Simiand, por Halbwachs, e um pouco menos pelos outros autores. Nisso, eu adquiro, de certa forma, uma massa de informaçóes que nunca tinha sido tratada, porque os durkheimianos, os sociólogos durkheimianos, enfim, os sociólogos que se interessavam pelo trabalho de Durkheim não tinham interesse em particular pela economia. E assim, quando comecei a fazer esse trabalho, encontrei aquele que era o papa, no bom sentido do termo porque era alguém que tinha domínio sobre o assunto: quando eu apresentei meus primeiros esboços a Philippe Besnard, ele ficou muito entusiasmado e muito contente, porque ele sabia que era um domínio que não tinha sido estudado. E assim ele me instigou a continuar trabalhando nisso. Então, é por acaso que vai haver, em um certo momento, uma ênfase em minha pesquisa sobre a herança durkheimiana, mas daí há uma coisa que é bastante evidente: na França, a sociologia tem como grande ancestral Durkheim; nós o estudamos e a vantagem em relação aos outros autores é que os textos estão em francês, então é mais cômodo. Eu não leio em alemão, por exemplo, então de Max Weber, eu li tudo o que estava disponível em francês, italiano, inglês, etc., mas eu não o li em alemão. Ademais, Durkheim é quem organizou a relação entre economia e sociologia de uma maneira diferente daquela de Weber e Pareto: como uma oposição, que retoma o ponto de vista de Comte e que depois será retomado por Bourdieu. Entáo, isso me coloca, de alguma forma, em uma perspectiva um pouco mais geral da sociologia econômica, digamos, dos filósofos franceses: Comte, Durkheim e Bourdieu são todos os três filósofos. Isso me permite ter esta filiação. Durkheim é importante por essa razão. Mas eu não apenas trabalhei a partir da perspectiva de Durkheim, uma vez que o segundo livro de sociologia econômica que escrevi é um livro de sociologia do conhecimento econômico. Nesse momento, estava usando, talvez esta seja uma expressão um tanto pretensiosa, mas digamos que estava usando 
um modelo que é weberiano. Assim, fiz uma leitura da história do desenvolvimento da economia política na França e Grã-Bretanha, de 1750 a 1850, e fiz esta leitura a partir, sendo este o objetivo do capítulo 1, de um modelo ou de uma tipologia, para ser mais modesto, de uma tipologia das quatro formas de desenvolvimento da economia: a economia formalmente racional, a economia materialmente racional e as economias que não são racionais porque estão relacionadas sejam às instituiçóes, sejam à economia moral do povo. E isso é uma base weberiana, explicitamente, que eu construí para fazer esse trabalho. Essa não é uma base durkheimiana. Eu não sou, digamos, completamente focado em uma abordagem durkheimiana. Para certos casos, podemos combinar os dois e, em outros casos, Weber oferece mais do que Durkheim. Nesse caso em específico, a referência era Weber e não Durkheim.

Entrevistador - Bem, insisto um pouco mais na abordagem durkheimiana, mesmo que haja essa afinidade weberiana também. Sobre isso, você escreveu na conclusão de um artigo de 2013 (Religiáo e economia em Durkheim: duas formas de coesáo social ?): "O ato de considerar o mercado como instituição e as instituiçóes mercantis que lhes são associadas obriga-nos a rejeitar a oposição entre a coesão religiosa e a incoesão econômica, presente n'As Formas, para investigarmos cuidadosamente as formas inerentes à coesão mercantil. Levar em conta as instituiçôes mercantis permite desenvolver as intuiçôes de Durkheim, seguindo os princípios que estabeleceu, para ultrapassar seus próprios limites. Uma maneira de fazer e pensar constitutiva da sociologia que ele próprio defendia" (STEINER, 2013, p. 45). Então, pergunto a você: a possibilidade de trabalhar na sociologia econômica hoje a partir de Durkheim seria, exatamente, prestando atenção aos limites da teoria social dele?

P. S. - Sim. Isso me desconcertou de alguma forma quando me dei conta que Durkheim nunca fala sobre o mercado. Na Division du travail social, ele fala sobre o contrato e da relaçáo de interesse que os atores têm entre si, mas o mercado como instituição nunca é estudado. Demorei algum tempo, talvez estivesse de alguma forma muito embebido em Durkheim para perceber isso. E a instituição da qual Durkheim fala é o contrato. Eventualmente, uma outra instituição é o agrupamento 
profissional, mas onde ele fala do mercado como instituição, como forma de solidariedade? Em nenhum lugar!

Entrevistador - Em nenhum lugar?

P. S. - Na minha leitura, sim. Eu posso ter perdido textos importantes. Eu náo acredito, mas isso pode acontecer. E me parece que a ideia que eu queria traduzir na passagem que você lembrou é que podemos usar Durkheim em estudos sobre as formas de solidariedade em um domínio particular de trocas que é o mercado, mas você tem que ir além de alguns dos seus limites, na medida em que ele não estuda o mercado. É nesse sentido que me parece que há pontos que permanecem obscuros sobre ele. Simiand apenas resolve uma parte disso, por meio dessa relação de conflito bastante sofisticada, mas nunca retomada, entre o patronato e os trabalhadores. Por isso, existe aí uma perspectiva conflitual do mercado de trabalho que é esboçada, que é uma maneira de conceber o mercado, mas Durkheim não considera isso. E então, é preciso ir além de seus limites. $\mathrm{O}$ outro ponto, se você quiser, no qual me parece que também há limites, é sobre a questão entre religião e economia. Durkheim, de fato, coloca em evidência algumas relaçóes entre economia e religião, mas isso se encontra relativamente escondido em Les formes élémentaires e, sobretudo, fica indexado às sociedades muito primitivas, e isso é explícito em Durkheim. Desse modo, não podemos entender a relação entre economia e religião apenas estudando os Aruntas da Austrália... existe a estrutura atual, existe a da Idade Média, etc., não devemos nos fechar no caso apresentado por Durkheim, devemos saber ultrapassar alguns de seus limites. Foi sobre isso que pensei.

Entrevistador - Esse é o problema. Como superar esses limites e continuar alinhado com essa perspectiva? É ainda possível permanecer alinhado com essa perspectiva durkheimiana?

P. S. - Sim, escute. Então, para isso, eu avançaria em duas sugestóes. A primeira, me parece, é o que tentei fazer em um dos capítulos do livro sobre o altruísmo. É para ver que Durkheim tem um programa de pesquisa que primeiramente se volta em direção à economia e, em seguida, um programa de pesquisa que o conduz para a religiấo. Quando ele se volta para a religião, ele não está mais com Simiand, ele está com Mauss. E quando 
Mauss intervém, vemos aparecer uma outra filiação distinta daquela sobre o mercado, que é a noção segundo a qual «a solidariedade é a dádiva», para ser direto. Parece-me que é uma verdadeira filiação também interessante. Assim, desse ponto de vista, se pode permanecer, penso eu, muito durkheimiano, fazendo um pouco como Caillé e o grupo do M.A.U.S.S., mas sem distender tanto quanto eles a ligação entre Durkheim e Mauss. Os dois trabalharam juntos e quebrar isso me parece inadequado. Se, contrariamente a essa forte distinção, traçamos um elo, parece-me que há toda uma via de reflexão que, de certo modo, tentei estudar com a questão do transplante de órgáos, porque lá o mercado foi proibido e é a dádiva que surge no lugar. Assim, pode-se ser durkheimiano e, na questão do altruísmo e de sua evolução, a filiação é, efetivamente, Durkheim-Mauss. Então, ainda há um vasto domínio. Esta é uma resposta inicial que eu faria, independentemente da que dei agora há pouco sobre o mercado como uma forma de coesão social, como uma forma de solidariedade que deve ser estudada de um modo durkheimiano. Eu náo faço isso nesse momento. E, depois, há uma segunda opção à qual me referia agora há pouco que me interessa e que é a questão das festas, não necessariamente religiosas, e a relação delas com a economia. Sobre isso, me parece que Durkheim é o único a oferecer as ferramentas. Weber nunca estudou as festas, Simmel tampouco. Pareto, na minha opinião, também não, ou talvez isso esteja em observações marginais. $\mathrm{O}$ único grande sociólogo e, finalmente, o único fundador da sociologia que tratou da festa é Durkheim em Les formes élémentaires. Acerca disso, há um tipo de reflexão possível que precisa ser desenvolvida ou usada, eventualmente indo contra Durkheim, ao dizer que, no mundo moderno, a separação entre a festa e a economia não é tão forte quanto Durkheim dizia em seu livro. Existem, pelo contrário, muitos elos entre os dois. A festa dinamiza a economia, mas a festa, sem uma atividade econômica, não funciona. Se vamos às praias de Aracaju e queremos festejar, precisamos de cervejas geladas. Precisamos de pessoas que façam a moqueca, os bons pratos, etc. E isso é trabalho, é economia. A festa e a economia vão bem juntas. Há uma tendência para pensar nelas como separadas. Mais uma razão para dizer que alguém pode ser durkheimiano na sociologia, cruzar coisas que me parecem novas, que não foram desenvolvidas. Iremos nos inspirar em Durkheim, mas não se pode aplicá-lo mecanicamente. 
Deve ser modificado. É preciso trabalhar nisso. Ademais, isto é o que ele pedia a seus discípulos.

Entrevistador -Uma pergunta final para terminarmos esta entrevista: no seu ponto de vista, quais são os objetos de pesquisa mais estimulantes e que merecem investigaçóes mais aprofundadas?

P. S. - Pessoalmente, no momento, estou interessado na sociologia da festa e dos eventos festivos. Acho que há pessoas que podem se interessar de uma maneira diferente, embora eu queira me concentrar não apenas no fato de as pessoas se reunirem, mas nas reunióes festivas das pessoas que querem se divertir, que querem fazer a festa. Não é algo religioso, nem político, nem são movimentos militantes, é encontro festivo. Os outros também são interessantes, mas aí eu acho que há um objeto que não foi muito estudado, porém que vale a pena ser. Porém, esses são meus interesses pessoais. Existe outra área que me interessa e para a qual eu já tenho uma colaboração com o Brasil, já que Nadya [Guimarães] está construindo um grupo com colegas mais jovens no Brasil sobre a questão do matching. Há cada vez mais no momento atual mecanismos que são configurados. São mecanismos automatizados que dirão que se tal aluno quer ir para a universidade e ele quer informaçóes, eles dizem: a melhor escolha para você é essa. Isso existe na França. Isso criou um grande problema porque era um sistema chamado APB [Admission Post-Bac], que foi considerado como inadequado por Macron, o novo presidente, e, em seu lugar, colocaram o "Parcoursup" (que cria um conflito entre o ministério e uma quantidade de departamentos universitários neste momento em que nós falamos). Em ambos os casos, são sistemas que fazem o que chamamos de matching. Há matching em sites de encontros amorosos, há matching para aluguel de AirBNB, há matching para transplante de órgãos e há matching para o mercado de trabalho. O matching é um fenômeno que não é desconhecido dos sociólogos. Coleman fala sobre isso, há estudos, mas se torna um objeto novo e até emergente com as grandes bases de dados e os softwares de matching. Aí temos um fenômeno social novo, já que para etapas essenciais da vida, a vida amorosa, a saúde, o trabalho, a universidade, temos dispositivos automatizados para reunir instituiçôes e indivíduos ou os indivíduos entre si. E para isso precisamos de bancos de dados. O que são as bases de dados? É uma forma de coletivo, sob forma informática, nos 
computadores. Esse é um exemplo de um novo fenômeno que os sociólogos, na minha opinião, devem investigar. As festas, o matching e, para além disso, eu empregaria a fórmula de Bourdieu: não há assuntos menores. A partir do momento em que sejam estudados de forma vigorosa e inovadora, você pode fazer a sociologia econômica das lixeiras!

Entrevistador - Das lixeiras?!

P. S. - É sério! Esse é um problema enorme para todas as cidades. É o caso do Brasil, é o caso em Paris, é o caso de todas as cidades. Existem milhóes de pessoas vivendo em um espaço muito limitado. Essas pessoas geram lixo. A sociologia econômica do lixo seria de considerável importância. É por isso que eu digo: a sociologia econômica das lixeiras, uma forma de brincadeira ou um tanto de provocação, mas aqui está um objeto que não pensamos antes e que me parece de considerável importância tanto quanto a sociologia econômica do mercado de carbono, que também é muito interessante e que aborda problemas semelhantes. A sociologia econômica das lixeiras é um exemplo de objeto menor, mas que não tem qualquer razáo para permanecer pequeno em termos de sua produtividade intelectual, sua produtividade acadêmica e do esclarecimento que traz às sociedades pelos estudos sociológicos que fazemos.

\section{Referências}

STEINER, P. Altruísmo, dons e troca simbólica. São Carlos: UNESP, 2016 a.

A sociología de Durkheim. Petropolis: Vozes, 2016b.

. Religião e economia em Durkheim: duas formas de coesão social? Revista Pós, Ciências

Sociais, Maranhão, v. 10, n. 19, p. 31-46, 2013.

A sociologia econômica, São Paulo: Atlas, 2006.

. Pourquoi la sociologie économique est-elle si développée en France? L'Année sociologique,

Paris, v. 55, n. 2, p. 391-416, 2005. 